\title{
A population-based study of the association between areca nut chewing and Type 2 diabetes mellitus in men (Keelung Community-based Integrated Screening programme No. 2)
}

\author{
T.-H. Tung ${ }^{1}$ Y.-H. Chiu ${ }^{2}$ L.-S. Chen ${ }^{2}$ H.-M. Wu ${ }^{3}$ B. J. Boucher ${ }^{4}$ T. H.-H. Chen ${ }^{5}$ \\ ${ }^{1}$ Department of Medicine Research and Education, Cheng Hsin Rehabilitation Center, Taipei, Taiwan \\ ${ }^{2}$ Institute of Health Informatics and Decision Making, School of Medicine, National Yang-Ming University, Taipei, Taiwan \\ ${ }^{3}$ Graduate Institute of Epidemiology, College of Public Health, National Taiwan University, Taipei, Taiwan \\ ${ }^{4}$ Centre for Diabetes and Metabolic Medicine, St Bartholemew's and the Royal London School of Medicine and Dentistry, \\ Queen Mary and Westfield College, London, UK \\ ${ }^{5}$ Institute of Preventive Medicine, College of Public Health, National Taiwan University, Taipei, Taiwan
}

\section{Abstract}

Aims/hypothesis. The aim of this study was to assess whether the diabetogenicity of areca nut (Areca cate$c h u$ or 'betel-nut'), which has previously been demonstrated experimentally in mice, independently contributes to the risk of hyperglycaemia or Type 2 diabetes in men in Taiwan, where the habit has become established relatively recently.

Methods. We used data from a population-based cross-sectional survey and a multiple-disease-screening programme that tested for hyperglycaemia, Type 2 diabetes and risk factors related to Type 2 diabetes. Data on habitual areca nut chewing were available for 14,816 men. Multiple logistic regression models were used to determine whether areca nut chewing was an independent risk factor for Type 2 diabetes.

Results. Compared with non-chewers, areca nut chewers had higher age-adjusted prevalence rates for hyperglycaemia (11.4\% vs $8.7 \%$ ) and Type 2 diabetes (10.3\% vs $7.8 \%)$. Areca nut chewing independently increased the risk of hyperglycaemia (adjusted odds ratio [OR] 1.19, 95\% CI 0.97-1.45) and Type 2 diabetes (adjusted OR 1.29, 95\% CI 1.04-1.60). The independent effects of duration of chewing were dose-dependent for Type 2 diabetes (adjusted OR 1.32 for the duration of 10-19 years and 1.41 for the duration of $\geq 20$ years), as were the effects of increased rates of areca nut chewing (adjusted OR 1.14 for $<10$ pieces/day, 1.30 for 10-19 pieces/day and 2.02 for $\geq 20$ pieces/day); similar findings were noted for hyperglycaemia.

Conclusions/interpretation. The habit of chewing areca nut independently contributes to the risk of both hyperglycaemia and Type 2 diabetes in Taiwanese men. This association is dose-dependent with respect to the duration of areca nut use and the quantity of areca nut chewed per day.

Keywords Areca nut $\cdot$ Betel $\cdot$ Hyperglycaemia Type 2 diabetes
Received: 7 January 2004 / Accepted: 1 June 2004

Published online: 27 October 2004

C) Springer-Verlag 2004

T. H.-H. Chen (

Institute of Preventive Medicine, College of Public Health, National Taiwan University, No. 19, Hsu-Chow Rd, Taipei,

Taiwan

E-mail: stony@episerv.cph.ntu.edu.tw

Tel.: +886-2-23587620

Fax: +886-2-23587707

Abbreviations: BUN, blood urea nitrogen · KCIS, Keelung Community-based Integrated Screening - LRT, likelihood ratio testing $\cdot$ OR, odds ratio

\section{Introduction}

In Taiwan, areca nut chewing has become one of the most popular lifestyle habits over the last 40 years. The habit of chewing the nut of the Areca catechu palm is commonly referred to in English as 'betelchewing', a term arising from the use of leaves from the creeping vine Piper betle to wrap up chopped nuts to form quids. Areca catechu is currently used by about 2 million Taiwanese people (approximately $10 \%$ of the population), particularly the male 'blue collar' workers and those with low levels of education [1]. The main varieties of chews used in Taiwan are those prepared by combining unripe areca fruit with a 
piece of the inflorescence (flower head) of the Piper betle vine and red lime paste, or by wrapping unripe areca fruit in leaves of the Piper betle vine with white lime paste [2]. It should be noted that no tobacco is added to the chews used in Taiwan.

Chewing areca nut has been found to significantly contribute to the development of oral cancer [3, 4], primary hepatocellular cancer $[5,6]$ and oesophageal carcinoma [7]. In addition, the arecal nitrosamines formed from the specific arecal alkaloids $[8,9]$ have been shown to be carcinogenic experimentally. Many nitrosamines are diabetogenic, and it has been suggested that arecal nitrosamines may be diabetogenic in man [10]. However, no population-based studies investigating the direct relationship between areca nut chewing and Type 2 diabetes have been performed to date. The habit of areca nut chewing is now common among Taiwanese men but, like Type 2 diabetes, this has only occurred over the last $20+$ years. This reduces the risk of confounding due to the possible inheritability of the diabetogenic effects of areca nut (as previously reported in experimental animals [9]) or of parental diabetes [11] in this population. This is of particular importance since the habit has been common for 2000 years or more in virtually all other countries where areca nut is used. Based on this fact, the aim of the present study was to investigate the dose-dependent effects of areca nut on the development of Type 2 diabetes in the Taiwanese population.

\section{Subjects and methods}

Study subjects. All data were derived from the Keelung Community-based Integrated Screening (KCIS) programme. This was a multiple-disease-screening programme that was carried out in Keelung, the northernmost county of Taiwan, between 1 January 1999 and 31 December 2001. Details of the study design and some preliminary results have been described elsewhere [12]. Briefly, a total of 42387 subjects (including 15,097 men and 27,290 women) were enrolled in the KCIS programme and attended a screening for Type 2 diabetes. Subjects with hyperglycaemia or Type 2 diabetes were diagnosed according to the criteria of the American Diabetic Association (ADA) as defined in 1999 [13]. Subjects with fasting plasma glucose levels of $\geq 6.1 \mathrm{mmol} / \mathrm{l}$ were defined as having hyperglycaemia and those with fasting plasma glucose levels of $\geq 7.0 \mathrm{mmol} / \mathrm{l}$ were defined as having Type 2 diabetes. Patients with previously diagnosed Type 2 diabetes were identified by questionnaire. As only 231 women either reported the use of areca nut or were ex-chewers, the present study focused on males alone. After the exclusion of a further 281 male subjects with incomplete data for areca nut use, the final study population on which the present analyses were based consisted of 14,816 subjects. This project was approved by the local health committee, which is run by the Taiwan Community-based Integrating Group [12]. Subjects gave their consent to participate in the on-site KCIS screening after being fully informed about the survey by public health nurses with formal documentation in Chinese.
Data collection. Data on behavioural risk factors (smoking, alcohol intake and areca nut chewing) were collected at one-toone interviews using a structured questionnaire. The main type of areca nut chews used in Keelung city are the so-called 'LaoHwa', which are prepared by combining portions of unripe areca nut with a piece of the inflorescence (flower head) of the Piper betle vine and red lime paste [2]. Subjects were divided into three categories according to areca nut use: (i) current chewers; (ii) non-chewers (never); and (iii) ex-chewers. The duration of areca nut use and the number of portions of areca nut chewed each day were also recorded.

To investigate whether demographic and socio-economic factors (occupation and education) differed between the areca nut chewers and the non-chewers, these data were also collected. Occupation was classified as in the study by Hashibe et al. [14]. Data on biological factors associated with the risk of Type 2 diabetes were also collected, including systolic blood pressure, diastolic blood pressure, BMI, total cholesterol, triglyceride, blood urea nitrogen, serum creatinine, uric acid and central obesity (as waist circumference). The univariate distribution of these factors is summarised in Table 1.

Statistical analysis. The prevalences of hyperglycaemia and Type 2 diabetes in chewers and non-chewers were compared using the chi square test. Subjects were classified into five groups according to age $(<40,40-49,50-59,60-69$ and $\geq 70$ years). Multiple logistic regression modelling was then used to investigate whether areca nut chewing had an independent effect on the risk of hyperglycaemia or of Type 2 diabetes after adjustment for age, risk factors associated with Type 2 diabetes and socioeconomic status. The models used were chosen to minimise residual confounding $[15,16]$. Continuous confounders were adjusted either as linear terms or by quintile distribution. The choice of which adjustment to use for each continuous variable was determined by testing for departure from linearity between two models, one including dummy variables and the other assuming linearity for the variables of interest using likelihood ratio testing (LRT). When the result of the LRT was significant, the confounder in question was included after stratification into quintiles, otherwise the linear data for the confounder was used. Trend analysis, based on LRT, was also used to define the models for the assessment of dose-response relationships of areca nut use with respect to the duration and the quantity or intensity (duration $\times$ quantity) of areca nut chewed [17]. A $p$ value of less than 0.05 was considered significant.

\section{Results}

Table 1 shows the distribution of demographic and biochemical data according to areca nut use. Table 2 shows the prevalence of areca nut use according to age. The average overall usage rate was $14.4 \%$. Table 3 shows that the unadjusted prevalence rate for hyperglycaemia was $9.3 \%$ in chewers and $10.7 \%$ in nonchewers $(p=0.046)$. However, when divided into five groups according to age (see Subjects and methods section), chewers aged 50-69 years had statistically higher prevalence rates for hyperglycaemia than nonchewers (age 50-59 years $p=0.032$, age 60-69 years $p=0.002$ ). As regards subjects aged less than 50 years, the prevalence rates for hyperglycaemia in chewers were still higher than those in non-chewers. This difference was not statistically significant for the group 
Table 1. Univariate distribution of demographic and biochemical variables categorized by areca nut chewing in men (KCIS programme, 1999-2001)

\begin{tabular}{|c|c|c|c|}
\hline \multirow[t]{2}{*}{ Variable } & \multicolumn{3}{|l|}{ Areca nut chewing } \\
\hline & Current or ex-chewers $(n=2120)$ & Non-chewers $(n=12,696)$ & Total $(n=14,816)$ \\
\hline Age (years) & $45.1 \pm 10.3$ & $55.6 \pm 13.9^{\mathrm{a}}$ & $54.1 \pm 14.0$ \\
\hline Physical activity (\% yes) & 82.3 & $86.9^{\mathrm{b}}$ & 86.2 \\
\hline Senior high school & 41.4 & 26.8 & 28.9 \\
\hline Junior high school or below & 48.8 & 53.0 & 52.4 \\
\hline \multicolumn{4}{|l|}{ Occupation (\%) } \\
\hline None & 21.8 & $37.6^{\mathrm{b}}$ & 35.3 \\
\hline Retired & 1.7 & 6.1 & 5.5 \\
\hline \multicolumn{4}{|l|}{ Biochemical variables } \\
\hline BMI $\left(\mathrm{kg} / \mathrm{m}^{2}\right)$ & $25.5 \pm 3.6$ & $24.9 \pm 3.5^{\mathrm{a}}$ & $25.0 \pm 3.5$ \\
\hline Waist circumference $(\mathrm{cm})$ & $85.7 \pm 9.6$ & $85.4 \pm 9.3$ & $85.4 \pm 9.4$ \\
\hline Systolic BP (mm Hg) & $128.2 \pm 20.0$ & $131.4 \pm 20.9^{a}$ & $131.0 \pm 20.8$ \\
\hline Diastolic BP (mm Hg) & $83.0 \pm 11.9$ & $82.5 \pm 11.6$ & $82.6 \pm 11.6$ \\
\hline Total cholesterol (mmol/l) & $5.02 \pm 1.03$ & $5.05 \pm 1.09$ & $5.05 \pm 1.08$ \\
\hline Triglyceride (mmol/l) & $1.99 \pm 2.13$ & $1.50 \pm 1.21^{\mathrm{a}}$ & $1.57 \pm 1.39$ \\
\hline BUN (mmol/l) & $0.54 \pm 0.16$ & $0.59 \pm 0.20^{\mathrm{a}}$ & $0.58 \pm 0.19$ \\
\hline Creatinine $(\mu \mathrm{mol} / \mathrm{l})$ & $95.28 \pm 28.35$ & $99.06 \pm 37.30^{\mathrm{a}}$ & $98.52 \pm 36.17$ \\
\hline Uric acid $(\mathrm{mmol} / \mathrm{l})$ & $0.38 \pm 0.10$ & $0.38 \pm 0.10$ & $0.38 \pm 0.10$ \\
\hline
\end{tabular}

Data are means \pm SD or percentages. a A $p$ value of less than 0.05 for the two sample independent $t$ tests was considered significant for continuous variables; ${ }^{b}$ a $p$ value of less than 0.05 for the chi square tests was considered significant for categorical variables

Table 2. Prevalence of areca nut chewing with age in men (KCIS programme, 1999-2001)

\begin{tabular}{|c|c|c|c|c|c|c|c|c|}
\hline \multirow[t]{2}{*}{ Age (years) } & \multirow[t]{2}{*}{$n^{\mathrm{a}}$} & \multicolumn{7}{|c|}{ Areca nut chewing } \\
\hline & & \multicolumn{2}{|c|}{ Current chewers } & \multicolumn{2}{|c|}{ Ex-chewers } & \multicolumn{2}{|c|}{ Non-chewers } & $p$ value for $\chi^{2}$ test \\
\hline$<40$ & 2707 & 398 & 14.7 & 331 & 12.2 & 1978 & 73.1 & $<0.0001$ \\
\hline $40-49$ & 3737 & 421 & 11.3 & 365 & 9.8 & 2951 & 78.9 & \\
\hline$\geq 70$ & 2819 & 19 & 0.7 & 24 & 0.9 & 2776 & 98.4 & \\
\hline Total & 14816 & 1148 & 7.8 & 972 & 6.6 & 12696 & 85.6 & \\
\hline
\end{tabular}

a See Subjects and methods section for details of population screened

aged 40-49 years $(p=0.18)$ and of borderline statistical significance in subjects younger than 40 years of age $(p=0.09)$. In subjects aged 70 years or older, nonchewers had only a marginally higher prevalence rate than chewers. These findings suggested that age was a confounding factor and should be adjusted for. The overall age-adjusted prevalence of hyperglycaemia was $11.4 \%$ in chewers and $8.7 \%$ in non-chewers $(p<0.0001)$. The age at which the prevalence of hyperglycaemia rose above $15 \%$ was younger in chewers than in non-chewers. Similar findings were noted for Type 2 diabetes (Table 3 ).

After adjusting for age, socio-economic status, and other biological factors, the adjusted odds ratios [ORs] for the association between areca nut use and the risk of hyperglycaemia and Type 2 diabetes were 1.19 


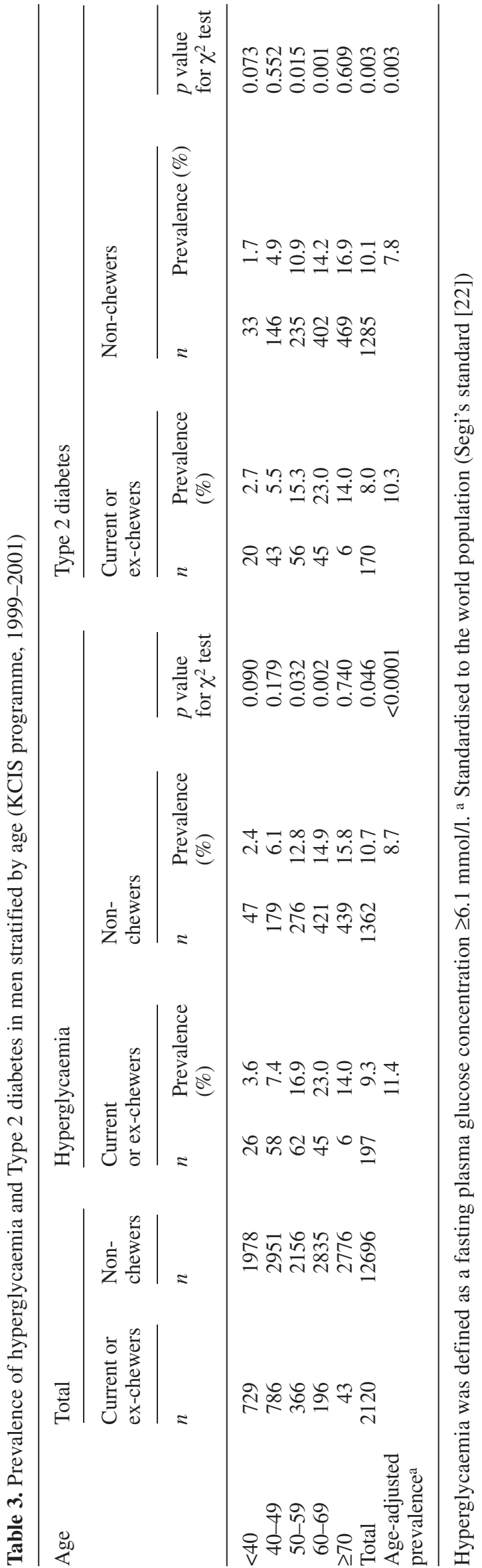

Table 4. Adjusted odds ratios for significant factors of hyperglycaemia or Type 2 diabetes in areca-nut-chewing men using multiple logistic regression models (KCIS programme, 1999-2001)

\begin{tabular}{lllllll}
\hline Model & \multicolumn{2}{l}{ Hyperglycaemia } & & \multicolumn{2}{c}{ Type 2 diabetes } \\
\cline { 2 - 3 } \cline { 5 - 6 } & OR & $95 \%$ CI & & OR & $95 \%$ CI \\
\hline $\begin{array}{llllll}\text { Adjusted for age } \\
\begin{array}{l}\text { Adjusted for age } \\
\text { and other confounders }\end{array}\end{array}$ & 1.39 & $1.17-1.64$ & & 1.41 & $1.18-1.68$ \\
\hline
\end{tabular}

Areca nut chewers $(n=2120)$ vs non-chewers $(n=12,696)$. Hyperglycaemia was defined as a fasting plasma glucose concentration $\geq 6.1 \mathrm{mmol} / \mathrm{l}$. ${ }^{\text {a }}$ Age was divided into five groups: $<40$, $40-49$, 50-59, 60-69 and $\geq 70$ years; b other confounders included obesity (yes/no), hypertension (yes/no), physical activity (high/low), education and occupation categorised as in Table 1, total cholesterol (quintiles), triglyceride (quintiles), creatinine (quintiles), uric acid (quintiles), BMI (quintiles), and log-transformed BUN (linear term); c confounders and their characteristics were similar to those in footnote $b$ except total cholesterol was adjusted as a linear term after log-transformation of values

(95\% CI $0.97-1.45)$ and 1.29 (95\% CI 1.04-1.60) respectively (Table 4).

After controlling for relevant factors, significant dose-response relationships were noted with respect to the duration of chewing and quantity of nuts chewed (Table 5). All trend tests were statistically significant $(p<0.05)$. Compared with non-chewers, the risk of Type 2 diabetes was 1.41 times higher (95\% CI 1.08-1.86) in those who had chewed areca nut for more than 20 years and 2.02 times higher $(95 \% \mathrm{CI}$ 1.31-3.09) in those who had chewed more than 20 pieces of areca nut per day. Similar findings, though of smaller magnitude, were noted for hyperglycaemia. Table 5 also shows the combined effect of usage rates and duration of use expressed as intensity (duration $x$ quantity). Trend tests for the intensity values divided into quartiles were statistically significant for hyperglycaemia $(p=0.01)$ and Type 2 diabetes $(p<0.01)$.

\section{Discussion}

The present study used a population-based design to investigate the association between the use of areca nut chews (the type prepared by combining areca nut, Piper betle vine leaf and lime paste) and hyperglycaemia and Type 2 diabetes. Three major findings of this study are in agreement with previous experimental work showing that feeding areca nut to young adult mice can induce permanent glucose intolerance in a significant proportion of animals [9].

Firstly, the associations between areca nut use and the risk of hyperglycaemia or Type 2 diabetes remained after adjustment for age, socio-economic status and potentially confounding lifestyle and biologi- 
Table 5. Multiple logistic regression models on the risk factors for the development of hyperglycaemia and Type 2 diabetes in men (KCIS programme, 1999-2001)

\begin{tabular}{|c|c|c|c|c|c|c|}
\hline \multirow[t]{2}{*}{ Variables } & \multicolumn{3}{|c|}{ Hyperglycaemia } & \multicolumn{3}{|c|}{ Type 2 diabetes } \\
\hline & OR & $95 \% \mathrm{CI}$ & Test for trend & OR & $95 \% \mathrm{CI}$ & Test for trend \\
\hline \multicolumn{7}{|c|}{ Duration of chewing areca nuts } \\
\hline $\begin{array}{l}\text { No chewing } \\
<10 \text { years } \\
10-19 \text { years } \\
\geq 20 \text { years }\end{array}$ & $\begin{array}{l}1.00 \\
0.74 \\
1.26 \\
1.35\end{array}$ & $\begin{array}{l}- \\
0.39-1.40 \\
0.87-1.81 \\
1.05-1.75\end{array}$ & $\begin{array}{l}\chi_{(1)}^{2}=5.62 \\
p=0.018\end{array}$ & $\begin{array}{l}1.00 \\
0.75 \\
1.32 \\
1.41\end{array}$ & $\begin{array}{l}- \\
0.37-1.50 \\
0.89-1.94 \\
1.08-1.86\end{array}$ & $\begin{array}{l}\chi_{(1)}^{2}=6.63 \\
p=0.010\end{array}$ \\
\hline \multicolumn{7}{|c|}{ Quantity of areca nuts chewed (per day) } \\
\hline $\begin{array}{l}\text { No chewing } \\
<10 \text { pieces } \\
10-19 \text { pieces } \\
\geq 20 \text { pieces }\end{array}$ & $\begin{array}{l}1.00 \\
1.18 \\
1.20 \\
1.47\end{array}$ & $\begin{array}{l}- \\
0.89-1.58 \\
0.80-1.78 \\
0.95-2.27\end{array}$ & $\begin{array}{l}\chi_{(1)}^{2}=4.05 \\
p=0.044\end{array}$ & $\begin{array}{l}1.00 \\
1.14 \\
1.30 \\
2.02\end{array}$ & $\begin{array}{l}- \\
0.83-1.56 \\
0.85-1.98 \\
1.31-3.09\end{array}$ & $\begin{array}{l}\chi_{(1)}^{2}=9.56 \\
p=0.002\end{array}$ \\
\hline \multicolumn{7}{|c|}{ Intensity of chewing (quantity $\times$ duration) ${ }^{b}$} \\
\hline $\begin{array}{l}\text { No chewing } \\
<1.3 \\
1.3-3.5 \\
3.5-9.3 \\
\geq 9.3\end{array}$ & $\begin{array}{l}1.00 \\
1.01 \\
1.04 \\
1.25 \\
1.62\end{array}$ & $\begin{array}{l}- \\
0.62-1.66 \\
0.67-1.62 \\
0.84-1.85 \\
1.14-2.31\end{array}$ & $\begin{array}{l}\chi_{(1)}{ }^{2}=6.46 \\
p=0.010\end{array}$ & $\begin{array}{l}1.00 \\
1.08 \\
1.13 \\
1.16 \\
1.93\end{array}$ & $\begin{array}{l}- \\
0.64-1.80 \\
0.71-1.80 \\
0.75-1.80 \\
1.35-2.77\end{array}$ & $\begin{array}{l}\chi_{(1)}^{2}=9.47 \\
p=0.002\end{array}$ \\
\hline
\end{tabular}

Hyperglycaemia was defined as a fasting plasma glucose level $\geq 6.1 \mathrm{mmol} / \mathrm{l}$. The results for 14816 subjects were analysed. a The confounders adjusted for in this model are identical to those listed in Table $4 ;{ }^{b}$ values are expressed as $\times 10^{4}$ piece-days

cal factors. This suggests an independent effect of this particular habit. Our findings, together with more recent population survey data from Papua New Guinea, strengthen the argument for the diabetogenicity of areca nut use [18].

In the present study, the younger age of onset of Type 2 diabetes in chewers compared with non-chewers is consistent with the fact that a study conducted in Coventry (UK) revealed that South Asian subjects developed Type 2 diabetes at an earlier age than the European subjects [19]. Furthermore, these individuals required supplemental hypoglycaemic medication more frequently and at a younger age than the Europeans [19]. The younger age of onset observed in our study also paralleled the increased prevalence of the areca nut habit in younger people, reflecting the comparatively recent uptake of the habit over the last 40 years.

The finding of significant dose-response relationships between areca nut use (both in terms of quantity and duration) and hyperglycaemia and Type 2 diabetes suggests that an active arecal agent is directly toxic to beta cells. It is possible that the diabetogenicity of arecal chews might be due to the lime paste used rather than the areca nut. However, there have been no reports to date to suggest that lime paste is either diabetogenic or carcinogenic, though it appears to have a local inflammatory effect in the mouth [20]. In addition, the hyperglycaemia reported experimentally in mice followed the feeding of areca nut without other chew components [9].
In contrast with a previous study conducted in the UK [21], significant direct associations were observed between areca nut use and clinically damaging increases in glycaemia. This discrepancy may reflect the much larger population examined in the present study. Alternatively, it may be due to the fact that the Bangladeshi Asians who took part in the UK study were from communities that have chewed betel-quids (areca nut) for thousands of years [21], whereas the current levels of areca nut use in Taiwanese men have only been reached over the last 40 years. In view of the degree of inheritability of increased glycaemia (with islet damage) that has been demonstrated experimentally in mice fed with areca nuts, the authors of the UK study speculated that the failure to find direct associations in areca-using communities where the habit was long standing may reflect confounding by the similar inheritability of diabetogenic effects in man. Furthermore, it was postulated that any association of environmental exposure to diabetogenic nitroso-compounds with diabetes would be more easily detected in populations where this particular risk factor had only recently been introduced [21]. Thus, the relationships found between Type 2 diabetes and arecal use in the present study are particularly pertinent, since the recent uptake of areca nut chewing by this population has provided a unique opportunity to test the postulated diabetogetogenicity of this habit in man.

In conclusion, we have demonstrated an association between areca nut chewing and Type 2 diabetes using a population-based study in a community in which the habit is of recent origin. 
Acknowledgements. We are indebted to Y.-D. Chen, P.-E. Wang, T.-T. Wang, Y.-L. Shih, H.-L. Kuo, H.-C. Lee, S.-Y. Hu, C.-L. Wu, Y.-F. Huang, H.-C. Chen and M.-S. Chung from the Health Bureau of Keelung City who were involved in organising and overseeing the KCIS programme, and to C.-H. Chen and B.V. North from the Chang-Gung Memorial Hospital of Keelung for advice on the reporting of the statistical methodology.

\section{References}

1. Ko YC, Chiang TA, Chang SJ, Hsieh SF (1992) Prevalence of betel quid chewing habit in Taiwan and related sociodemographic factors. J Oral Pathol Med 21:261-264

2. Yang YH, Lee HY, Tung S, Shieh TY (2001) Epidemiological survey of oral submucous fibrosis and leukoplakia in aborigines of Taiwan. J Oral Pathol Med 30:213-219

3. International Agency for Research on Cancer (1985) IARC monographs on the evaluation of carcinogenic risk of chemicals to humans, vol. 37. Tobacco habits other than smoking: betel-quid and areca nut chewing; and some related nitrosamines. International Agency for Research on Cancer, Lyon, pp 141-202

4. Ko YC, Huang YL, Lee CH, Chen MJ, Lin LM, Tsai CC (1995) Betel quid chewing, cigarette smoking and alcohol consumption related to oral cancer in Taiwan. J Oral Pathol Med 24:450-453

5. Sun CA, Wu DM, Lin CC et al. (2003) Incidence and cofactors of hepatitis $\mathrm{C}$ virus-related hepatocellular carcinoma: a prospective study of 12,008 men in Taiwan. Am J Epidemiol 15:674-682

6. Tsai JF, Chuang LY, Jeng JE et al. (2001) Betel quid chewing as a risk factor for hepatocellular carcinoma: a casecontrol study. Br J Cancer 84:709-713

7. Wu MT, Lee YC, Chen CJ et al. (2001) Risk of betel chewing for oesophageal cancer in Taiwan. Br J Cancer 85:658-660

8. Jeng JH, Chang MC, Hahn LJ (2001) Role of areca nut in betel quid-associated chemical carcinogenesis: current awareness and future perspectives. Oral Oncol 37:477-492

9. Boucher BJ, Ewen SWB, Stowers JM (1994) Betel nut (Areca catechu) consumption and the induction of glucose intolerance in adult CD1 mice and in their F1 and F2 offspring. Diabetologia 37:49-55
10. Boucher BJ, Mannan N (2002) Metabolic effects of the consumption of Areca catechu. Addict Biol 7:103-110

11. Chen KT, Chen CJ, Gregg EW, Engelgau MM, Narayan KM (2001) Prevalence of Type 2 diabetes mellitus in Taiwan: ethnic variation and risk factors. Diabetes Res Clin Prac 51:59-66

12. Chen THH, Chiu YH, Luh DL et al. (2004) Communitybased multiple screening model: design, implementation, and analysis of 42,387 participants. Cancer 100:1734-1743

13. American Diabetes Association (1999) American Diabetes Association: clinical practice recommendations 1999. Diabetes Care 22 [Suppl 1]:S1-S114

14. Hashibe M, Jacobe BJ, Thomas G et al. (2003) Socioeconomic status, lifestyle factors and oral premalignant lesions. Oral Oncol 39:664-671

15. Austin PC, Brunner LJ (2004) Inflation of the type I error rate when a continuous confounding variable is categorized in logistic regression analyses. Stat Med 23:1159-1178

16. Becher H (1992) The concept of residual confounding in regression models and some applications. Stat Med 11: 1147-1158

17. Clayton D, Hill M (1993) Statistical models in epidemiology. Oxford University Press, Oxford

18. Benjamin AL (2001) Community screening for diabetes in the National Capital District, Papua New Guinea: is betelnut chewing a risk factor for diabetes? P N G Med J 44:101-107

19. Simmons D, Powell MJ (1993) Metabolic and clinical characteristics of south Asians and Europeans in Coventry. Diabet Med 10:751-758

20. Lee MJ, Hsu JD, Lin CL, Lin MH, Yuan SC, Wang CJ (2002) Induction of epidermal proliferation and expressions of PKC and NF-kappaB by betel quid extracts in mouse: the role of lime-piper additives in betel quid. Chem Biol Interact 140:35-48

21. Mannan N, Boucher BJ, Evans SJW (2000) Increased waist size and weight in relation to consumption of Areca catechu (betel-nut): a risk factor for increased glycaemia in Asians in east London. Br J Nutr 83:267-275

22. Waterhouse J, Muri CS, Correa P, Powell J (1976) Cancer incidence in five continents, Vol 3. IARC Scientific Publications, Lyon 